\title{
Single-cell quantification of Bax activation and mathematical modelling suggest pore formation on minimal mitochondrial Bax accumulation
}

\author{
H Düssmann ${ }^{1}$, M Rehm ${ }^{1}$, CG Concannon ${ }^{1}$, S Anguissola ${ }^{1}$, M Würstle ${ }^{1}$, S Kacmar ${ }^{1}$, P Völler ${ }^{2}$, HJ Huber ${ }^{1,3}$ and JHM Prehn ${ }^{\star, 1}$
}

Mitochondrial outer membrane permeabilisation (MOMP) during apoptosis is triggered by the activation and oligomerisation of Bax and Bak, but a quantification of these processes in individual cells has not yet been performed. Single-cell imaging of Bax translocation and oligomerisation in Bax-deficient DU-145 cells expressing CFP-Bax and YFP-Bax revealed that both processes started only minutes before or concomitantly with MOMP, with the majority of Bax translocation and oligomerisation occurring downstream of MOMP. Quantification of YFP-Bax concentrations at mitochondria revealed an increase of only $1.8 \pm 1.5 \%$ at MOMP onset. This was increased to $11.2 \pm 3.6 \%$ in bak-silenced cells. These data suggested that Bax activation exceeded by far the quantities required for MOMP induction, and that minimal Bax or Bak activation may be sufficient to trigger rapid pore formation. In a cellular automaton modelling approach that incorporated the quantities and movement probabilities of Bax and its inhibitors, activators and enablers in the mitochondrial membrane, we could re-model rapid pore formation kinetics at submaximal Bax activation.

Cell Death and Differentiation (2010) 17, 278-290; doi:10.1038/cdd.2009.123; published online 11 September 2009

Apoptosis is an important physiological cell death process during development, and a key cell death pathway for the elimination of damaged or superfluous cells in the adult. In the 'mitochondrial' or 'intrinsic' apoptosis pathway, the permeabilisation of the mitochondrial outer membrane permeabilisation (MOMP) represents the key decisive process. ${ }^{1}$ MOMP enables the release of mitochondrial intermembrane proteins into the cytosol which then activate a family of cytosolic cysteine proteases, the caspases. Bax and Bak are multidomain proapoptotic $\mathrm{Bcl}-2$ family proteins required for the process of MOMP. ${ }^{2}$ Although Bak is localised to mitochondria in nonapoptotic cells, large quantities of Bax are found in the cytosol and only translocate to mitochondria during apoptosis. ${ }^{3}$ To activate MOMP, Bax and Bak undergo specific conformational changes that enable both proteins to anchor in the mitochondrial outer membrane and to oligomerise. ${ }^{4-6}$ Although the mechanisms of Bax and Bak activation during apoptosis is still an area of intensive research, evidence is growing that specific proapoptotic proteins of the Bcl-2 protein super-family, in particular the Bcl-2 homology-domain 3 (BH3)-only proteins tBid and Bim, may be able to directly activate Bax and Bak. ${ }^{5-7}$ Bax and Bak homo-tetramers and higher oligomers are believed to physically form the release channels in the mitochondrial outer membrane large enough to allow for release of intermembrane proteins. ${ }^{7,8}$
The release of the mitochondrial intermembrane protein cytochrome $c$ (Cyt-C) through these channels can trigger the formation of a multiprotein complex called the apoptosome. ${ }^{1}$ The apoptosome binds and activates caspase- 9 , which subsequently activates effector caspases-3 and $-7 .^{1}$ The release of Cyt-C also causes a rapid, initially caspase-independent mitochondrial membrane potential depolarisation. ${ }^{9-12}$ MOMP and mitochondrial $\mathrm{Cyt}-\mathrm{C}$ release also have significant functions in the 'extrinsic' apoptosis pathway activated by death receptors. Here, death ligand-induced caspase-8 activation leads to cleavage of the $\mathrm{BH}$-only protein Bid into tBid, which in turn activates Bax and/or Bak. This provides a crosstalk between these two apoptosis pathways. ${ }^{4,5,7,13}$

As MOMP can also activate caspase-independent cell death programs, it is considered a key event in multiple forms of stress-induced cell death. ${ }^{14}$ Single-cell imaging studies using Cyt-C-GFP or other GFP- or fluorescently labelled mitochondrial intermembrane proteins have demonstrated that MOMP is a rapid process, completed in cells within minutes if not seconds. ${ }^{10,12,15}$ Although these studies suggested a high efficiency of the permeabilisation process, quantitative insights into the initiation of MOMP and the respective roles of Bax and Bak in this process have so far primarily been obtained from studies using artificial membranes and liposomes ${ }^{5,7,8}$ but are still lacking from experiments in living cells within an intact

\footnotetext{
${ }^{1}$ Department of Physiology and Medical Physics, Royal College of Surgeons in Ireland, Dublin 2, Ireland; ${ }^{2}$ Institute of Molecular Cell Biology, Faculty of Earth and Live Sciences, Vrije Universiteit, Amsterdam, The Netherlands and ${ }^{3}$ Siemens Ireland, Dublin 2, Ireland

${ }^{*}$ Corresponding author: JHM Prehn, Department of Physiology and Medical Physics, Royal College of Surgeons in Ireland, 123 St. Stephen's Green, Dublin 2, Ireland. Tel: + 3531402 2255; Fax: + 3531402 2447; E-mail: prehn@ rcsi.ie

Keywords: Bax; cellular automaton; FRET; mitochondrial outer membrane permeabilisation; systems biology

Abbreviations: AOTF, acousto optical tunable filter; CA, cellular automaton; CFP, cyan fluorescent protein; CHX, cycloheximide; Cyt-C, cytochrome $C$; FRET, fluorescence resonance energy transfer; FWHM, full-width half maximum; GFP, green fluorescent protein; $\Delta \Psi_{\mathrm{M}}$, mitochondrial membrane potential; MOMP, mitochondrial outer membrane permeabilisation; STS, staurosporine; tBid, truncated Bid; TRAIL, tumour necrosis factor-related apoptosis inducing ligand; YFP, yellow fluorescent protein

Received 26.2.09; revised 16.7.09; accepted 28.7.09; Edited by D Vaux; published online 11.9.09
} 
biological environment. We here performed a quantitative confocal microscopy and mathematical modelling study of the temporal and spatial dynamics of Bax translocation and oligomerisation relative to MOMP initiation in single living cells.

\section{Results}

Characterisation of Bax-deficient DU-145 cells expressing YFP-Bax. To establish a valid reporter model for Bax signalling, DU-145 cells, which are devoid of endogenous Bax expression were stably transfected with expression vectors for YFP-Bax and/or CFP-Bax. DU-145 cells overexpressing wild-type nontagged $\mathrm{Bax}^{16}$ served as an internal control. YFP- and CFP-Bax was expressed in the DU-145 cells after transfection as evidenced by immunoblotting using antibodies against Bax and GFP (Figure 1a). Probing of membranes with the Bax antibody suggested that the level of FP-Bax expression was somewhat lower than the high level of Bax expression in DU-145-Bax cells, but comparable to the physiological Bax level in HeLa cells. Bak expression was not compromised by the YFP-Bax fusion protein (Figure 1b). We next tested whether YFP-Bax, similar to wild-type Bax, was able to sensitise DU-145 cells to apoptosis activated by the intrinsic or extrinsic pathway. Expression of YFP-Bax significantly enhanced the sensitivity of DU-145 cells to staurosporine (STS) $(1 \mu \mathrm{M})$ and TRAIL-induced apoptosis $(100 \mathrm{ng} / \mathrm{ml}$ and $1 \mu \mathrm{g} / \mathrm{ml} \mathrm{CHX)}$ to a similar extent as untagged Bax (Figure 1c).

Similar to untagged Bax, the YFP-Bax fusion proteins also externalised an $\mathrm{NH}_{2}$-terminal epitope of the Bax protein (amino acids 12-24) during apoptosis, a conformational change required for Bax's proapoptotic activity. ${ }^{17}$ This was evidenced by confocal immunofluorescence analysis using the conformation-specific 6A7 Bax-antibody (Figure 2a) raised against the $\mathrm{NH}_{2}$-terminal epitope of the Bax protein, which is exposed on 'full' Bax activation. ${ }^{7,18}$ In all individual cells analysed, YFP-Bax activation (as evidenced by the $6 \mathrm{~A} 7$ antibody and detected in the red channel, Alexa 594) was associated with a significant clustering of YFP-Bax fluorescence detected in the YFP channel. Similar results were obtained in DU145-Bax cells expressing untagged Bax (Figure 2a; Supplementary Figure 1a). Quantification revealed no significant difference in Bax versus YFP-Bax activation detected with the $6 \mathrm{~A} 7$ antibody after $6 \mathrm{~h}$ of STS or TRAIL treatment (Supplementary Figure 1b). Furthermore, YFP-Bax translocation was associated with a re-distribution of mitochondrial Cyt-C into the cytosol (Figure $2 b$ ) as evidenced by immunofluorescence analysis. Cells that exhibited a
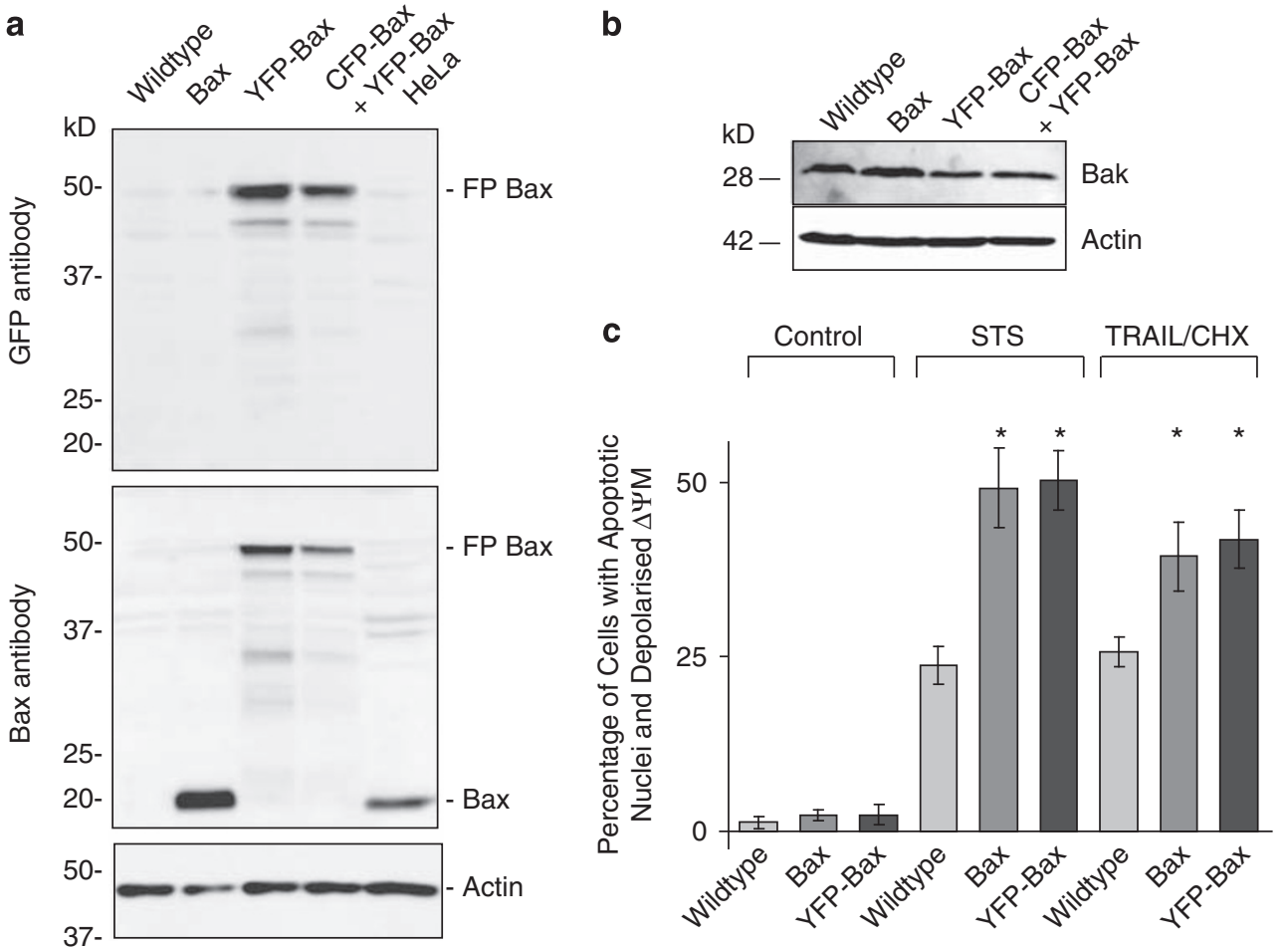

Figure 1 Bax-deficient DU-145 cells as a model to detect Bax signalling using fluorescent-protein-Bax fusion proteins (FP-Bax). (a) Immunoblots of whole-cell extracts show the expression levels of Bax, YFP-Bax and CFP-Bax in the different DU-145 clones used in this study. HeLa cells expressing native Bax are shown in comparison. Proteins were detected with a GFP or Bax antibody. Actin served as loading control. (b) The expression of Bak is not compromised by the over expression of Bax or FP-Bax as shown in immunoblots of whole-cell extracts of the different DU-145 clones used in this study. Actin served as loading control. (c) YFP-Bax sensitises to extrinsic and intrinsic apoptosis. DU-145 cells, DU-145-Bax and DU-145-YFP-Bax cells were treated with $1 \mu \mathrm{M}$ STS for $6 \mathrm{~h}$ or $100 \mathrm{ng} / \mathrm{ml}$ TRAIL plus $1 \mu \mathrm{g} / \mathrm{ml} \mathrm{CHX}$ for $6 \mathrm{~h}$, subsequently stained, and analysed for low mitochondrial membrane potential and nuclear morphology (Mitotracker Red, Hoechst 33258$)(n \geqslant 5$ independent treatments, $\geqslant 550$ cells counted per group, bars indicate mean \pm S.E.M., *significant to wildtype; $P<0.05$, one-way ANOVA and post hoc Tukey test) 
normal, mitochondrial pattern of Cyt-C immunofluorescence but showed significant YFP-Bax clustering could not be detected. These results suggested that we had established a valid cell culture model suitable for the quantification of Bax activation during apoptosis.

Bax oligomerisation detected with FRET coincides with $\Delta \Psi_{M}$ depolarisation during live cell time-lapse imaging. We next investigated Bax translocation and oligomerisation during apoptosis in CFP-Bax and YFP-Bax expressing DU-145 cells by time-lapse confocal microscopy and FRET analysis. We first tested the ability of our system to detect Bax oligomerisation during apoptosis. Bax molecules are expected to be in close proximity during the oligomer formation step. Using the donor de-quenching method, we could detect a significant increase in the FRET between CFP-Bax and YFP-Bax in apoptotic DU-145 cells (Figure $3 a-c$ ) that were identified by a loss of Tetramethylrhodamine Methylester (TMRM) fluorescence. We could not detect any FRET in CFP-Bax/YFP-Bax expressing DU-145 cells under control conditions, suggesting that a detectable oligomerisation step is absent under physiological conditions (Supplementary Figure 2).

We then performed single-cell time-lapse imaging experiments in DU-145 cells expressing CFP-Bax and YFP-Bax, and evaluated FP-Bax oligomerisation and accumulation in mitochondria in relation to MOMP (Figure 3d-e). MOMP was indirectly determined with the membrane potential sensor TMRM. $^{9}$ Earlier studies have demonstrated that MOMP is immediately followed by an initially caspase-independent depolarisation of the $\Delta \Psi_{M}{ }^{9,12,19-21}$ (see also Supplementary Figure 4). This approach had the advantage of limited spectral overlap and high sensitivity, and furthermore avoided the need for triple plasmid transfections and its associated artefacts. We referred to the onset of the decrease in the TMRM signal as the internal time of reference for each cell, and followed Bax signalling using the yellow fluorescent protein (YFP) and cyan fluorescent protein (CFP) fluorescence changes at 2-min time intervals (Figure 3d). For subsequent image analysis, the image of the cell was split into two compartments: (1) polarised mitochondria indicated by TMRM fluorescence (index: 'Mito'), (2) cell compartments not containing polarised mitochondria (index: 'Cyto'). By definition, the latter cell compartment included volumes with depolarised mitochondria. Splitting the cell into these two compartments enhanced the sensitivity of the measurements for the detection of activation steps before MOMP (see below).

Using this approach, we were able to detect CFP-Bax/YFPBax oligomerisation during apoptosis (see Figure $3 e$ for representative single-cell kinetics). In 12 out of 25 cells treated with STS, and 8 out of 30 cells treated with TRAIL/CHX, CFP$\mathrm{Bax} / \mathrm{YFP}-\mathrm{Bax}$ oligomerisation in mitochondria was detectable before a decrease in $\Delta \Psi_{\mathrm{M}}$. On average, however, the onset time of the increase in the FRET efficiency in the mitochondrial regions did not differ significantly from the onset of $\Delta \Psi_{\mathrm{M}}$ depolarisation (Figure 3f; Supplementary Figure 3), and the majority of CFP-Bax/YFP-Bax oligomerisation occurred downstream of $\Delta \Psi_{M}$ depolarisation (Figure $3 d-f$ ).

We next investigated YFP-Bax translocation kinetics in response to STS and TRAIL/CHX. The separation of the fluorescence images into the 'Mito' and the 'Cyto' compartments enabled us to detect a YFP-Bax increase in the mitochondrial compartment upstream of $\Delta \Psi_{\mathrm{M}}$ depolarisation in 9 out of 25 cells treated with STS, and in 8 out of 30 cells treated with TRAIL/CHX, but again the majority of YFP-Bax translocation occurred downstream of $\Delta \Psi_{\mathrm{M}}$ depolarisation. Statistically, the onset of YFP-Bax accumulation at mitochondria coincided with the onset of $\Delta \Psi_{M}$ depolarisation (Figure 3f; Supplementary Figure 3 ) and was not significantly different from the onset of CFP-Bax/YFP-Bax oligomerisation (FRET increase). We also noted that the quantification of YFP-Bax translocation by analysing changes in the standard deviation (S.D.) of the whole-cell YFP-Bax fluorescence represented a less sensitive analysis method (Figure $3 f$ ). In conclusion, these experiments suggested that submaximal Bax accumulation and Bax oligomerisation at mitochondria may be sufficient for the initiation of MOMP and the execution of apoptosis, and that the majority of Bax activation occurred downstream of MOMP.

\begin{abstract}
Single-cell quantification of YFP-Bax accumulation in polarised mitochondria during apoptosis. As the kinetics of YFP-Bax accumulation at polarised mitochondria was indistinguishable from that of CFP-Bax/YFP-Bax oligomerisation in the above imaging experiments, we next restricted our experiments to the detection of YFP-Bax accumulation at polarised mitochondria. These experiments could be performed with a significantly higher spatial and temporal resolution (full-width half maximum (FWHM) of optical section reduced to $1.5 \mu \mathrm{m}$ and time interval between measurements reduced to $1 \mathrm{~min}$ ), as this approach reduced potential photostress by eliminating the necessity of short wavelength CFP excitation. Untreated cells maintained their mitochondrial membrane potentials on prolonged imaging (22 h) and continued to proliferate on stage (Supplementary Figure 5). In addition to this, we also performed an absolute single-cell quantification of YFP-Bax protein concentrations in the individual cells monitored by confocal microscopy. For this approach, a detailed calibration of confocal YFP protein fluorescence signals was conducted (Figure 4a).
\end{abstract} Figure 2 YFP-Bax undergoes activation by conformational change during apoptosis of DU-145 cells. (a) YFP-Bax activation resembles native Bax activation in DU-145 cells as
detected in confocal scans of immunostains with the conformation sensitive $6 \mathrm{AT}$-antibody against active Bax. In comparison to untreated control cells (first panel), YFP Bax activation
was analysed in response to $100 \mathrm{ng} / \mathrm{ml}$ TRAIL/1 $\mu \mathrm{g} / \mathrm{ml} \mathrm{CHX}$ (second panel) or $1 \mu \mathrm{M} \mathrm{STS} \mathrm{(third} \mathrm{panel).} \mathrm{In} \mathrm{comparison,} \mathrm{native} \mathrm{Bax} \mathrm{activation} \mathrm{in} \mathrm{response} \mathrm{to} \mathrm{both} \mathrm{drugs} \mathrm{was} \mathrm{analysed}$
in DU-145 Bax cells (fourth and fifth panel). During TRAIL/CHX or STS-induced apoptosis, YFP-Bax underwent immunoreactive conformational changes and mitochondrial
translocation identical to native Bax. The controls in DU- 145 cells expressing native Bax as well as the stainings with only the secondary antibody furthermore confirmed specificity of
the readouts in the $6 \mathrm{A7}$ and YFP channels. Scale bars: $20 \mu \mathrm{m}$. (b) The translocation of YFP-Bax appears to coincide with the release of cytochrome $c$ as detected in single-cell
confocal z-projection. Native cytochrome $c$ was detected by immunostaining in DU-145 cells that stably express YFP-Bax. Scale bar: $10 \mu \mathrm{m}$ 


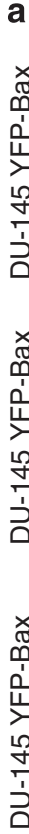

a

Bax 6 A7

YFP-Bax

Overlay

শั

亭

장

๓

는

늘

ᄂ

한응

등

原

๓ิ

号以

证

ডั

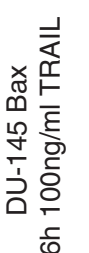

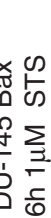
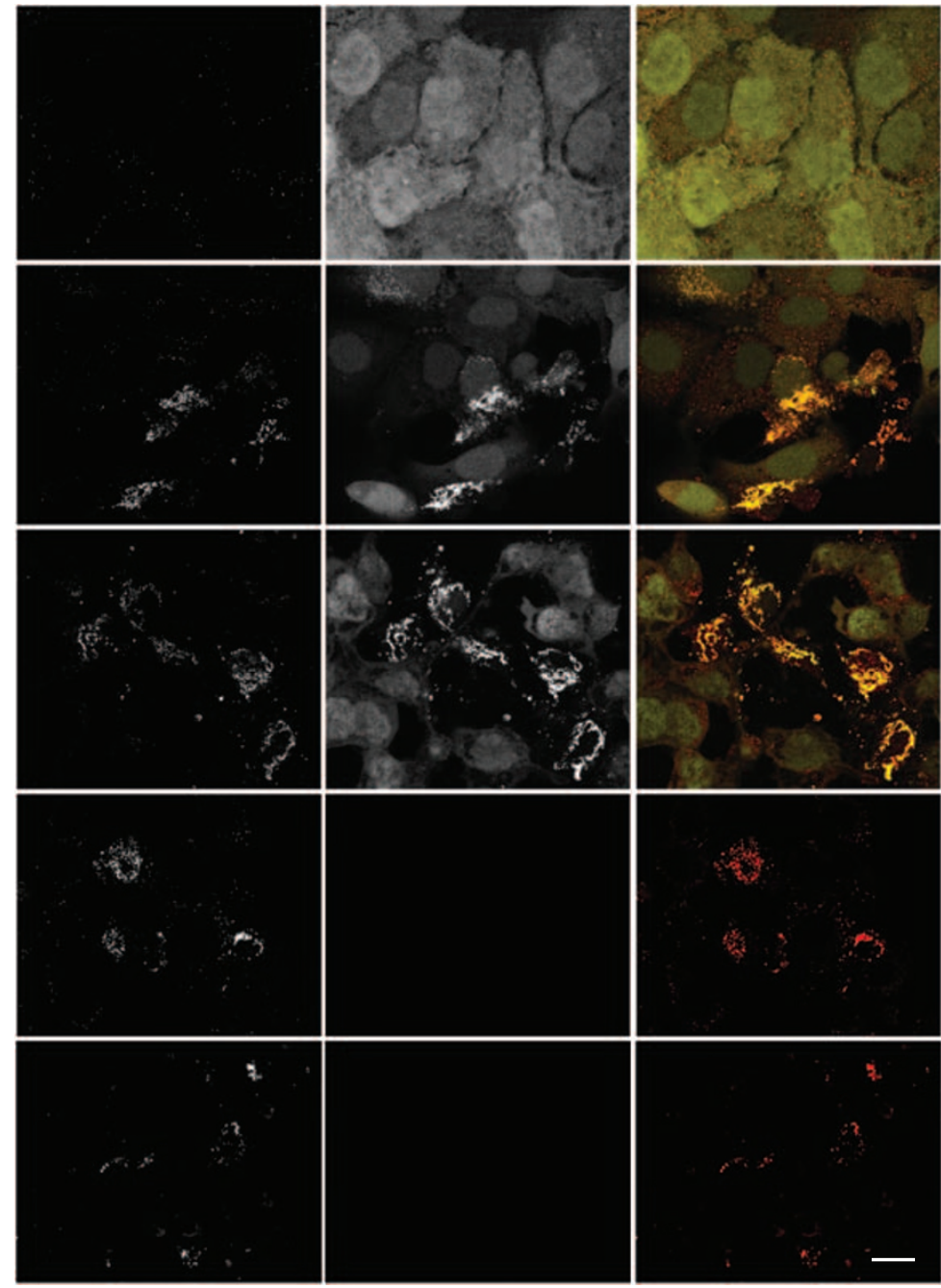

C. $3 x^{2}$

2nd AB only

YFP-Bax

Overlay
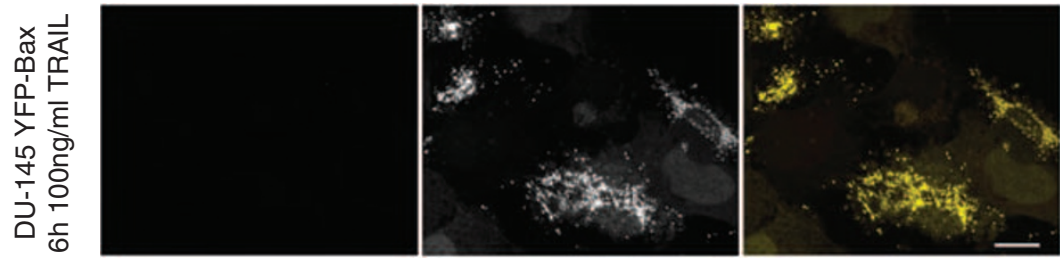

b

native Cyt-C

YFP-Bax

Overlay

DU-145

YFP-Bax

Control
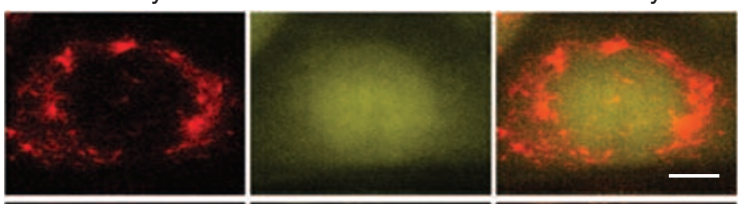

DU-145

YFP-Bax

6h $1 \mu \mathrm{M}$

STS
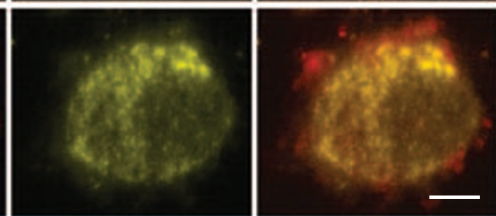
a
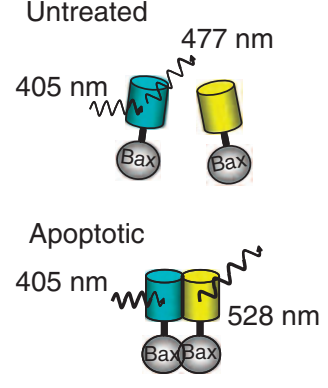

$405 \mathrm{~nm} 477 \mathrm{~nm}$
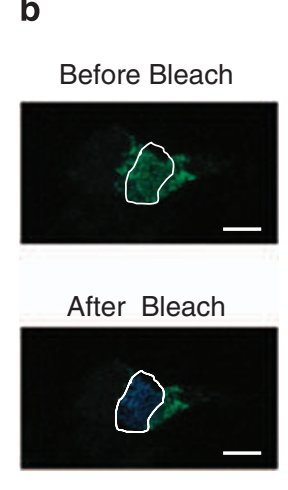

c

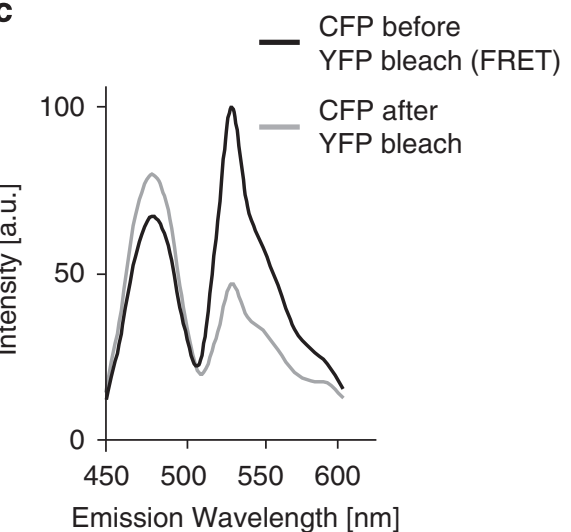

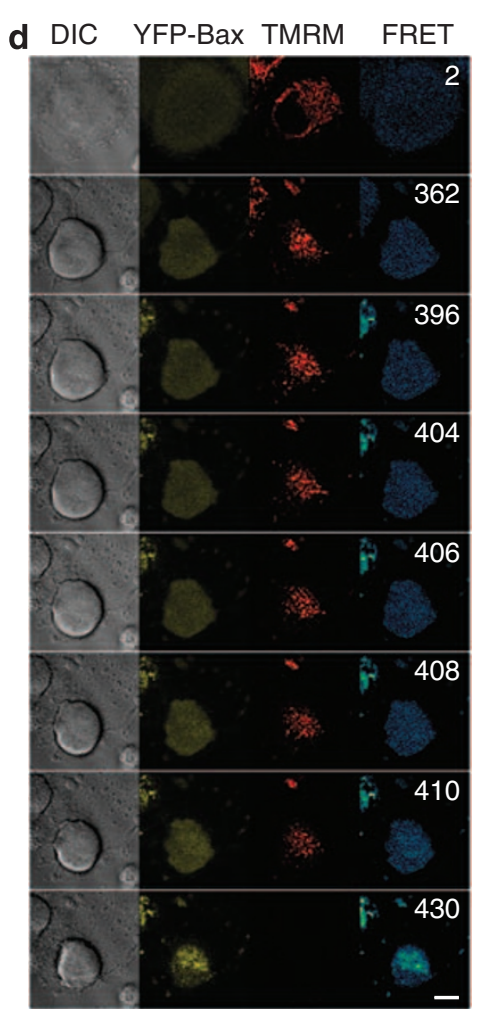

Time [min]

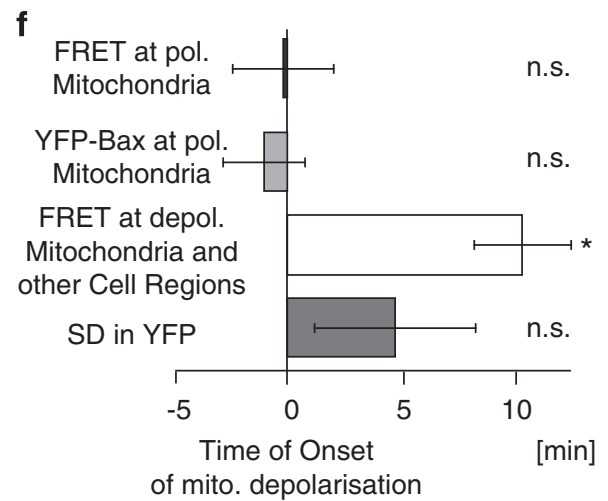

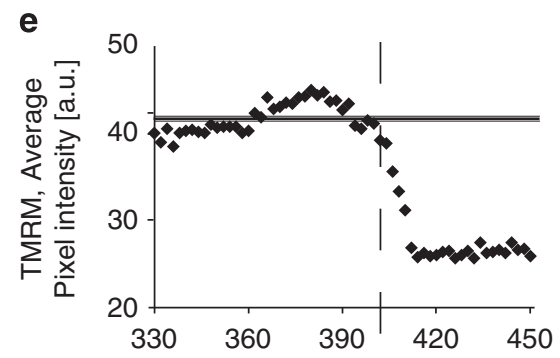
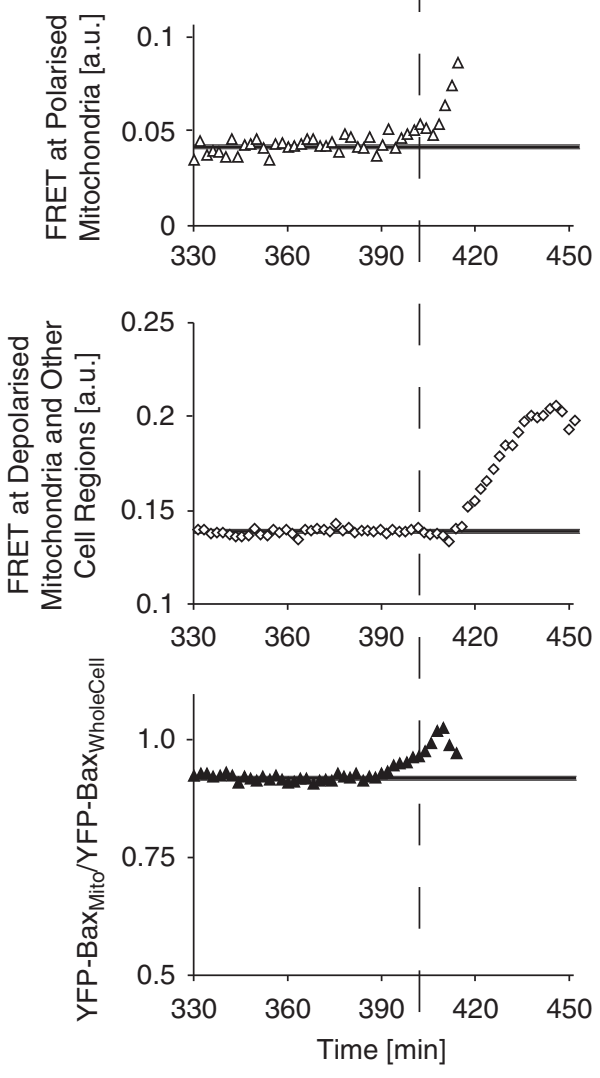
In these experiments, we could detect a significant accumulation of YFP-Bax at polarised mitochondria in DU145 cells during apoptosis (see Figure $4 b, c$ for representative single-cell kinetics and $4 \mathrm{~d}$ for quantifications). At control conditions, we determined the average basal expression of YFP-Bax and its cell-to-cell variability to be $3.16 \pm 0.34 \mu \mathrm{M}$ within the polarised mitochondria compartment. This was comparable to a YFP-Bax concentration of $3.16 \pm 0.36 \mu \mathrm{M}$ measured in the TMRM-negative, 'cytosolic' compartment.

From the noise of the baseline signals obtained from individual cells, we calculated the average detection limit for increases in the YFP-Bax signal as $0.037 \pm 0.007 \mu \mathrm{M}$ (representing a translocation of $1.1 \%$ YFP-Bax) at our experimental conditions. During apoptosis, the concentration of mitochondrial YFP-Bax increased significantly up to the time point of $\Delta \Psi_{\mathrm{M}}$ depolarisation, but only by $0.166 \pm 0.069 \mu \mathrm{M}$ during STS treatment, and $0.118 \pm 0.037 \mu \mathrm{M}$ during TRAIL/CHX treatment (Figure $4 d$ ), representing $5.3 \%$ and $3.7 \%$ of the total YFP-Bax, respectively. The onset time of YFP-Bax accumulation in the individual YFP-Bax expressing DU-145 cells is depicted in Figure $4 \mathrm{e}$ and suggested that in some DU-145 cells, the onset of YFP-Bax translocation may have occurred after the onset of $\Delta \Psi_{\mathrm{M}}$ depolarisation. We thus hypothesised that in these cells the presence of Bak may have contributed to the initiation of MOMP.

Effect of Bak knockdown on mitochondrial YFP-Bax accumulation. To test this hypothesis, we co-transfected DU-145 cells with YFP-Bax and either an siRNA targeting Bak or a nontargeting control siRNA (scrambled siRNA). Control experiments demonstrated that the Bak siRNA potently reduced Bak protein expression in DU-145 cells (Figure $5 \mathrm{a}$ ), and potently reversed the sensitivity of the large majority of DU-145 cells to STS or TRAIL/CHX treatment (Figure 5b).

We then determined YFP-Bax accumulation in mitochondria in relation to $\Delta \Psi_{\mathrm{M}}$ depolarisation during STS-induced apoptosis, using the same image acquisition parameters as described in the earlier chapter (see Figure $5 c$ and $d$ for representative single-cell images and traces). The translocation kinetics of YFP-Bax reflected by the increase of the ratio $R=F\left(Y F P_{\text {Mito }}\right) / F\left(Y F P_{\text {WholeCell }}\right)$ showed a significant differ- ence between the average onset time of YFP-Bax translocation in bak-silenced cells compared with the control cells (Figure 5e). We also detected a significantly enhanced accumulation of YFP-Bax at mitochondria at the onset of $\Delta \Psi_{\mathrm{M}}$ depolarisation (Figure $\left.5 \mathrm{f}\right)$. Analysis of all traces $(n=25)$ showed an increase of $0.476 \pm 0.163 \mu \mathrm{M}$ in the Bak knockdown cells compared with $0.063 \pm 0.052 \mu \mathrm{M}$ in the control cells transfected with scrambled siRNA $(n=23)$. This represented an increase of $11.2 \pm 3.6 \%$ over baseline in bak-silenced cells compared with $1.8 \pm 1.5 \%$ in cells transfected with scrambled siRNA ( $P=0.013$; $t$-test and Levene's test). The basal expression level of YFP-Bax was $3.47 \pm 0.89 \mu \mathrm{M}$ in cells co-transfected with scrambled siRNA compared with $4.59 \pm 0.63 \mu \mathrm{M}$ in bak-silenced cells (no significant difference, t-test $(P=0.3))$.

\section{Mathematical modelling of Bax pore formation} kinetics. We finally attempted to provide a mathematical explanation for the experimentally detected, high sensitivity of mitochondria to a submaximal Bax accumulation. As stochastic processes cannot be ignored when biological processes involve relatively small quantities of reaction partners and the interaction of these partners has profound biological consequences, we implemented a cellular automaton (CA) modelling approach of Bax-dependent MOMP $^{22,23}$ (see Materials and Methods and Supplementary Methods). The CA-model incorporated the hit, reaction, and movement probabilities as well as quantities of Bax and its inhibitors, activators, and enablers in the outer mitochondrial membrane (Supplementary Methods; Supplementary Figure 6a). The model was adapted to a Bak-deficient background, as this approach enabled a direct comparison of the modelling results to the experimentally determined YFP-Bax concentration kinetics in the DU-145 bak gene silencing experiments, in which interference from endogenous Bak (or Bax) could be largely excluded. The model incorporated a two-step activation of Bax, consisting of an initial Bax activation/translocation step (AcBax), and a second activation step requiring the interaction of Bax with an activator present within the mitochondrial outer membrane (AcBax*, 'direct activation model'). ${ }^{7}$ Alternatively, the second activation step was modelled to occur 'spontaneously' at

\footnotetext{
Figure 3 Kinetics of Bax oligomerisation on the single-cell level as detected by FRET resemble kinetics of Bax translocation to polarised mitochondria. (a) Scheme of the CFP-Bax/YFP-Bax FRET approach. In untreated cells, Bax molecules do not interact and thus do not allow for resonance energy transfer between donor (CFP) and acceptor (YFP) fluorophores. During apoptosis, Bax interaction results in close proximity of donor and acceptor, allowing for YFP emission on CFP excitation. Acceptor photobleaching results in donor unquenching and serves as control for FRET. (b, c) Acceptor photobleaching in a DU-145 cell expressing CFP-Bax and YFP-Bax undergoing apoptosis after treatment with $3 \mu \mathrm{M}$ STS shows an increase in the donor (CFP) fluorescence intensity and a decrease in the sensitised YFP emission. YFP was bleached using $100 \%$ of the $514 \mathrm{~nm}$ line of the Argon laser running at $50 \%$ of its maximal power until no further decrease of the YFP fluorescence could be observed. Fluorescence emission spectra were recorded before and after the bleaching process using $4 \%$ excitation intensity of the $405 \mathrm{~nm}$ laser with the spectral detector set to a resolution of $\Delta \lambda=10.75 \mathrm{~nm}$. Scale bar in confocal scans $=10 \mu \mathrm{m}$ (d) Time-lapse imaging of a representative DU-145 cell expressing CFP-Bax and YFP-Bax, stained with $30 \mathrm{nM}$ TMRM and treated with $3 \mu \mathrm{M}$ STS. Time stamps indicate time after STS addition. Scale bar $=10 \mu \mathrm{m}$. TMRM indicates polarised mitochondria. The TMRM image was used for cell segmentation to measure Bax translocation to and oligomerisation at mitochondria (see Materials and Methods). (e) Single-cell kinetics plotted for the cell presented in (d). The vertical dashed line indicates the onset of mitochondrial depolarisation (TMRM channel). Bax translocation to and oligomerisation at polarised mitochondria (fourth and second panel, respectively) preceded the onset of TMRM loss, whereas Bax oligomerisation in depolarised mitochondria and other cell regions was only detected later (third panel). (f) Quantification and sensitivity of Bax translocation/oligomerisation measurements during STS-induced apoptosis. Bax translocation to and oligomerisation at polarised mitochondria seem to coincide in DU-145 cells. Bax oligomerisation in the rest of the cell was detected only with a significant delay. Whole-cell analysis of YFP-Bax redistribution (S.D. of the YFP signal) was less sensitive than the segmentation approach for polarised mitochondria. The onset of $\Delta \Psi_{M}$ depolarisation was taken as the time of reference. Bax oligomerisation in the remaining cell (FRET at depolarised mitochondria and other cell regions) was significantly delayed to the FRET increase at polarised mitochondria ( $n=25$ cells from nine experiments analysed, $P<0.05$, paired sample $t$-test). Data from TRAIL/CHX-induced apoptosis are shown as Supplementary Figure 2
} 
a

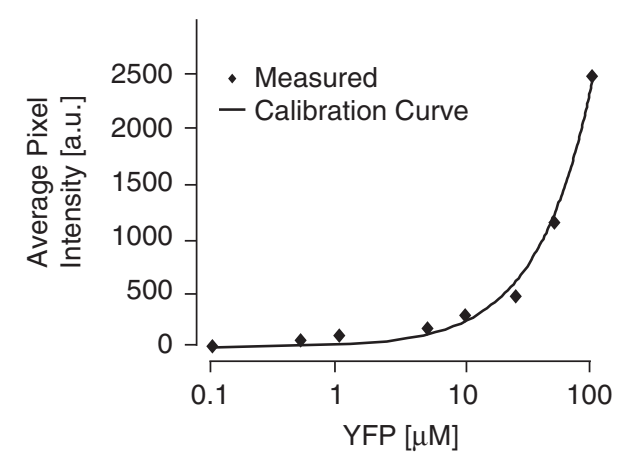

c

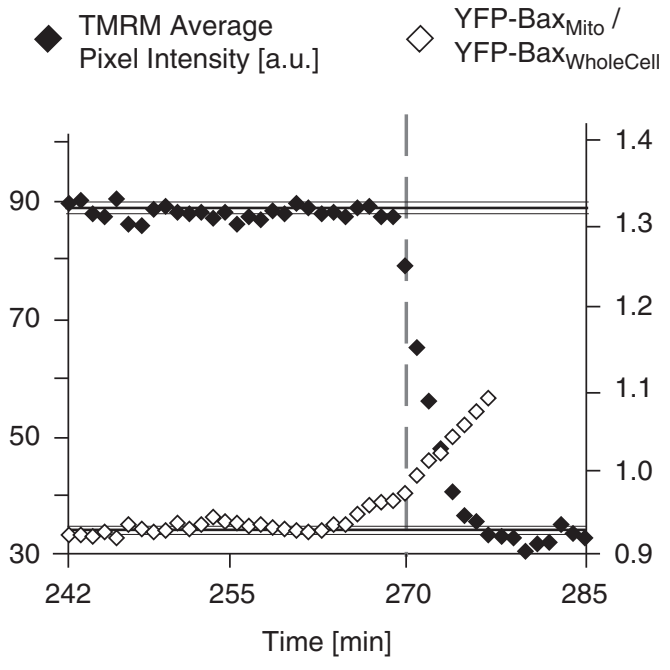

b

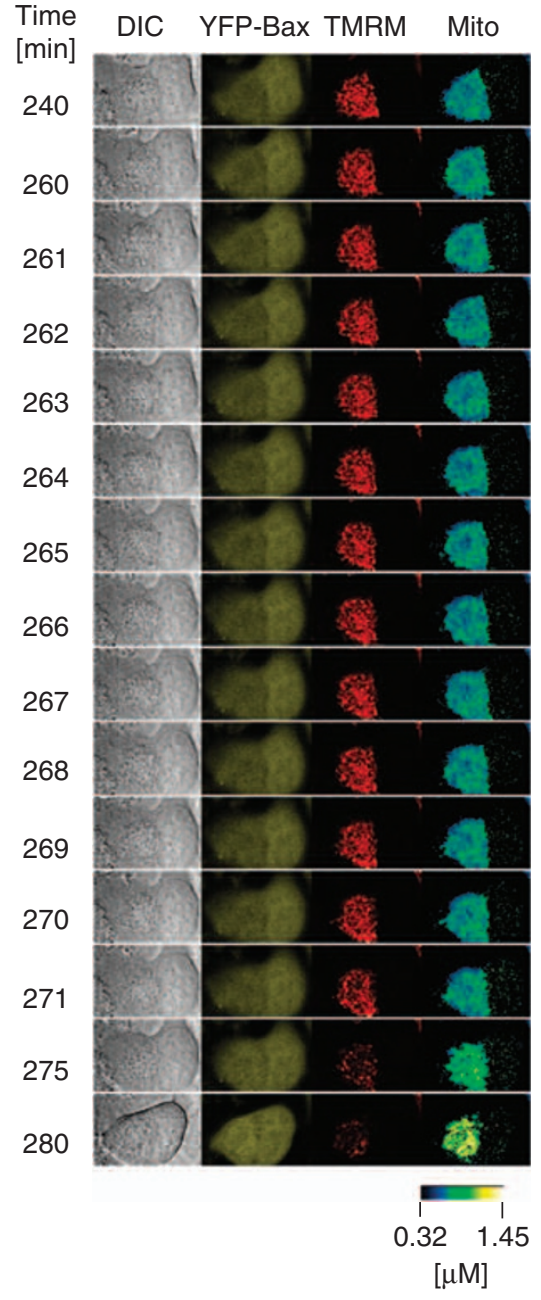

d

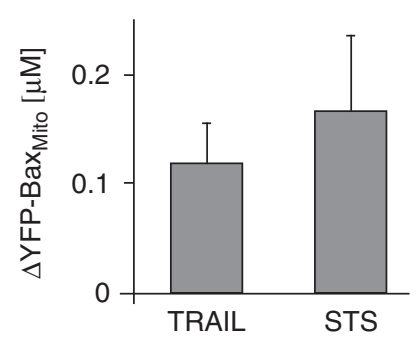

e TRAIL

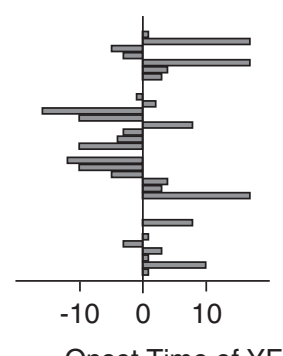

STS

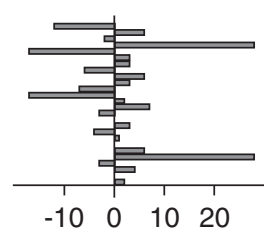

Onset Time of YFP-Bax Translocation [min]

Figure 4 Fluorescence calibration allows quantification of mitochondrial YFP-Bax accumulation during MOMP initiation. (a) Fluorescence calibration for absolute YFP quantification by confocal imaging. Purified YFP was used to correlate detected YFP fluorescence intensities with YFP concentrations across three orders of magnitude. For the higher concentrations, the average intensities were rescaled to the intensity scale of the most sensitive measurement setting (see Materials and Methods for details). (b) Quantification of intracellular YFP-Bax concentrations at polarised mitochondria. Images show a representative DU-145 cell treated with $3 \mu \mathrm{M}$ STS. The TMRM channel was used to segment polarised mitochondrial regions. The pseudo-colour scale indicates the YFP-Bax concentrations corresponding to the measured fluorescence intensities. Time stamps indicate time after stimulus addition. (c) Bax translocation to mitochondria precedes mitochondrial depolarisation. Corresponding to Figure 3, single-cell kinetics show that YFP-Bax increased at polarised mitochondria before onset of mitochondrial depolarisation (vertical dashed line). (d) Similar amounts of YFP-Bax have translocated to mitochondria at the onset of mitochondrial depolarisation during STS or TRAIL/CHX-induced apoptosis. The concentration change of YFP-Bax was quantified from $n=26$ cells from three independent experiments for STS and from $n=35$ cells from four independent experiments for TRAIL/CHX-induced apoptosis. YFP-Bax increases were significantly above the baseline noise ranges measured in the mitochondrial compartments before drug addition (paired samples $t$-test, $P<0.05$ or 0.007 for STS or TRAIL/ $\mathrm{CHX}$ treatments, respectively). (e) The onset of YFP-Bax translocation did not differ significantly from the onset of $\triangle \Psi_{\mathrm{M}}$ depolarisation in both STS and TRAIL/CHX-treated cells as calculated from the same data set as presented in (d). Data are shown as average \pm S.E.M. 
different probability rates ranging from 1 to 10 events per 1000 Bax molecules per $0.5 \mathrm{~s}$ (indirect activation model) (Supplementary Figure 7). The experimentally determined YFP-Bax concentration kinetics at mitochondria (Figure 5c; Supplementary Figure $6 \mathrm{~b}$ ) served to define the proapoptotic input into the model.

Repeated modelling of Bax pore formation kinetics (i.e. the formation of Bax tetramers and higher oligomers) in the 'direct activation' modelling approach and adapting the experimentally determined concentration kinetics revealed that single Bax pores could be formed in mitochondrial membranes on average $0.28 \pm 0.25 \mathrm{~min}$ before the onset of $\Delta \Psi_{\mathrm{M}}$ depolarisation (Figure 6; Supplementary Movie 1). Of note, the model also calculated a rapid, nonlinear increase in the probability of Bax pore formation subsequent to the formation of the first pores. The stochastic effects decreased when the number of Bax oligomers accumulated at mitochondria increased, and were in fact negligible when Bax accumulated at mitochondria in concentrations corresponding to the experimentally determined YFP-Bax concentration at the onset of $\Delta \Psi_{\mathrm{M}}$ depolarisation. The re-modelling approach therefore confirmed our hypothesis that Bax pores can be formed within mitochondria on submaximal Bax accumulation, and provided a mathematical explanation for the rapidity of the pore formation process. The 'indirect activation' modelling yielded similar pore formation kinetics when the model assumed a 'spontaneous' conversion of 3 out of 1000 Bax molecules into active Bax molecules per $0.5 \mathrm{~s}$ (Supplementary Figure 7).

\section{Discussion}

MOMP is a key process during the activation of caspasedependent and caspase-independent apoptosis pathways. ${ }^{1}$ We here performed a single-cell imaging analysis in human DU-145 cancer cells to obtain quantitative, spatiotemporal data of the process of Bax translocation and oligomerisation in an intact cellular environment during apoptosis.

Single-cell imaging of Bax activation. Several earlier reports have performed GFP-Bax imaging experiments during apoptosis and have described that, similar to the findings in our study, the majority of the cytoplasmic GFP. Bax pool translocates to mitochondria or mitochondriaassociated clusters during apoptosis.3,6,24,25 However, although GFP-Bax translocation precedes nuclear apoptosis and gross morphological alterations during apoptosis, ${ }^{3}$ a sharp distinction of GFP-Bax translocation and mitochondrial permeabilisation has been proven to be more difficult. $^{25-27}$ In an earlier study, Zhou and Chang $^{28}$ reported CFP-Bax translocation to mitochondria preceding the release of Smac-YFP, albeit at a reduced temporal resolution. The authors also demonstrated the hetero-oligomerisation of CFP-Bax and YFP-Bak in initially smaller and later larger aggregates that co-localised to mitochondria during apoptosis. Clearly, the expression of Bak, which can substitute for Bax in most apoptosis paradigms, ${ }^{2}$ or the expression of endogenous Bax protein may interfere with GFP-Bax apoptosis signalling, and decrease the detection sensitivity in confocal GFP time-lapse experiments. Therefore, we used quantitative confocal YFP-Bax imaging in Bax-deficient DU-145 cells, and investigated the effect of Bak on YFP-Bax apoptosis signalling using a gene silencing approach. Furthermore, by using image segmentation algorithms to optimise the detection of mitochondrial YFP-Bax accumulation at polarised mitochondria, we also achieved a significantly higher sensitivity than analysing whole-cell YFP-Bax redistribution patterns. Despite the fact that YFP-Bax appeared to be activated similar to Bax (Figure 2; Supplementary Figure 1), we cannot fully exclude that small differences in activation exist between Bax and YFP-Bax, which could limit the conclusions from our imaging studies.

Even under these conditions, we could detect only minimal YFP-Bax accumulation and YFP-Bax/CFP-Bax oligomerisation at mitochondria before the onset of $\Delta \Psi_{M}$ depolarisation. This allowed us to conclude that submaximal YFP-Bax activation may be sufficient to induce MOMP. One limitation of our imaging approach is that the TMRM-based imaging of $\Delta \Psi_{\mathrm{M}}$ depolarisation, which was chosen to decrease spectral overlap and increase the sensitivity of our imaging approach, reports MOMP with a mean delay of $36 \pm 16 \mathrm{~s}$ (Supplementary Figure 4). A correction for this delay for the Bak-silenced cells would result in slightly lower YFP-Bax concentration at mitochondria at the onset of MOMP. This would correspond to 100 molecules/mitochondrium, equivalent to an amount of $30 \mathrm{nM}$ of the measured $\triangle \mathrm{YFP}-\mathrm{Bax}_{\text {Mito }}$ of $476 \pm 163 \mathrm{nM}$. Also, we cannot fully exclude that YFP-Bax is already present but loosely attached to mitochondrial membranes may have got activated and inserted into mitochondrial membranes without a concomitant increase in mitochondrial YFP-Bax fluorescence. However, our studies in the bak-silenced DU-145 cells showed significantly higher levels of YFP-Bax accumulation at the time of mitochondrial depolarisation, suggesting that indeed mitochondrial YFP-Bax fluorescence accumulation represents an excellent reporter of YFP-Bax activation. A recent study has also suggested that membrane localisation of $\mathrm{Bax}$ is required for its activation and interaction with the $\mathrm{BH} 3-$ only protein tBid. ${ }^{7}$ Furthermore, in recent work we also provided evidence that MOMP inducers, once activated, will translocate within seconds to mitochondria. ${ }^{15,29}$ Nevertheless, even at optimised sensitivity at nonphototoxic conditions, we still detected mitochondrial depolarisation, indicative of MOMP, before the onset of mitochondrial Bax accumulation in YFP-Bax-expressing DU-145 cells. As this was much less frequently observed in cells in which bak gene expression was silenced, it is possible that such cell-to-cell variability arose from different endogenous levels of Bak protein expression, or from different protein expression levels of other Bcl-2 family proteins.

Using FRET between CFP-Bax and YFP-Bax, we similarly detected that mitochondrial Bax oligomerisation was tightly coupled with the YFP-Bax translocation and mitochondrial depolarisation process. We could not detect basal levels of Bax dimers/multimers by FRET analysis, neither in the cytosol nor at mitochondria of un-stimulated control cells (Supplementary Figure 2a). Likewise, we could not detect any increase in cytosolic Bax dimerisation during apoptosis before the onset of $\Delta \Psi_{\mathrm{M}}$ depolarisation. ${ }^{30}$ Our results therefore suggest that the process of Bax oligomerisation is confined to cell death signalling, and occurs at the level of the 
a

Bak

Scrambled siRNA Bak siRNA $\begin{array}{llllll}10 & 25 & 50 & 10 & 25 & 50\end{array}[\mathrm{nM}]$$$
-
$$

C

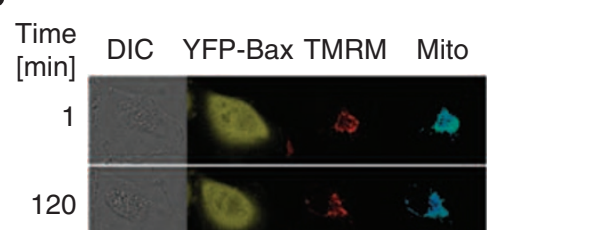

24

480

720

780

$$
780
$$

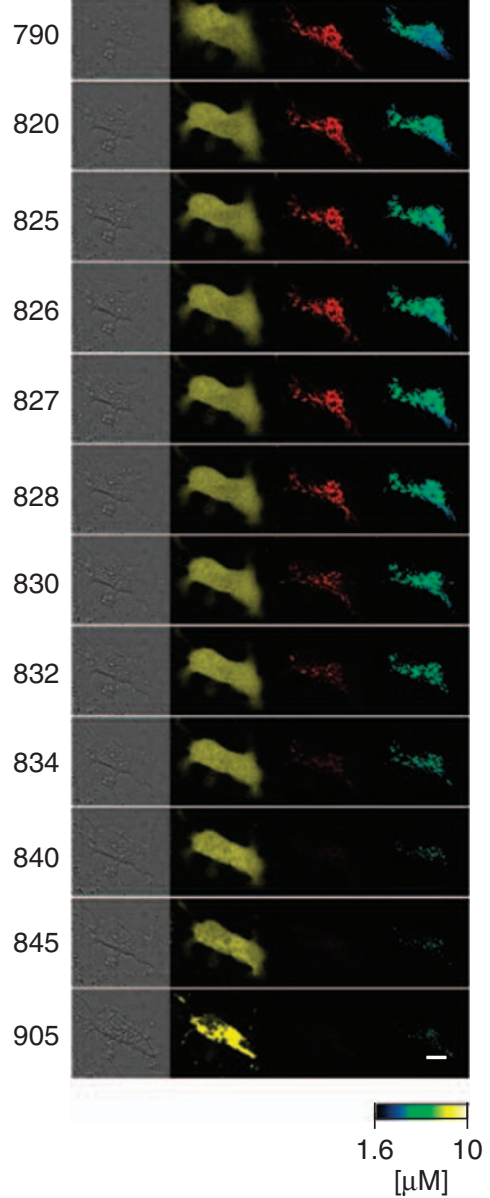

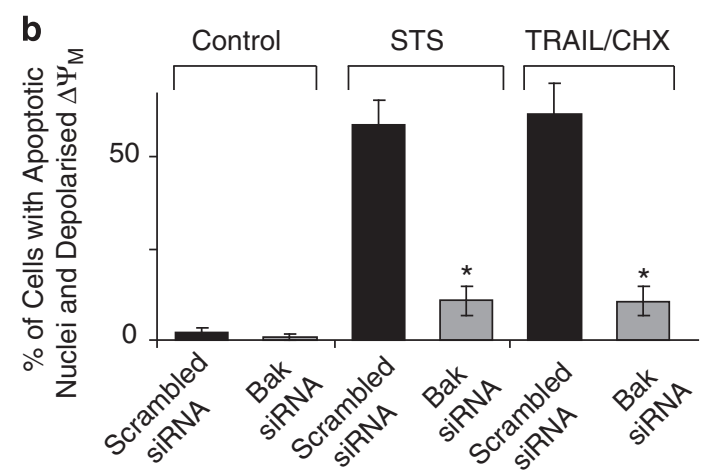
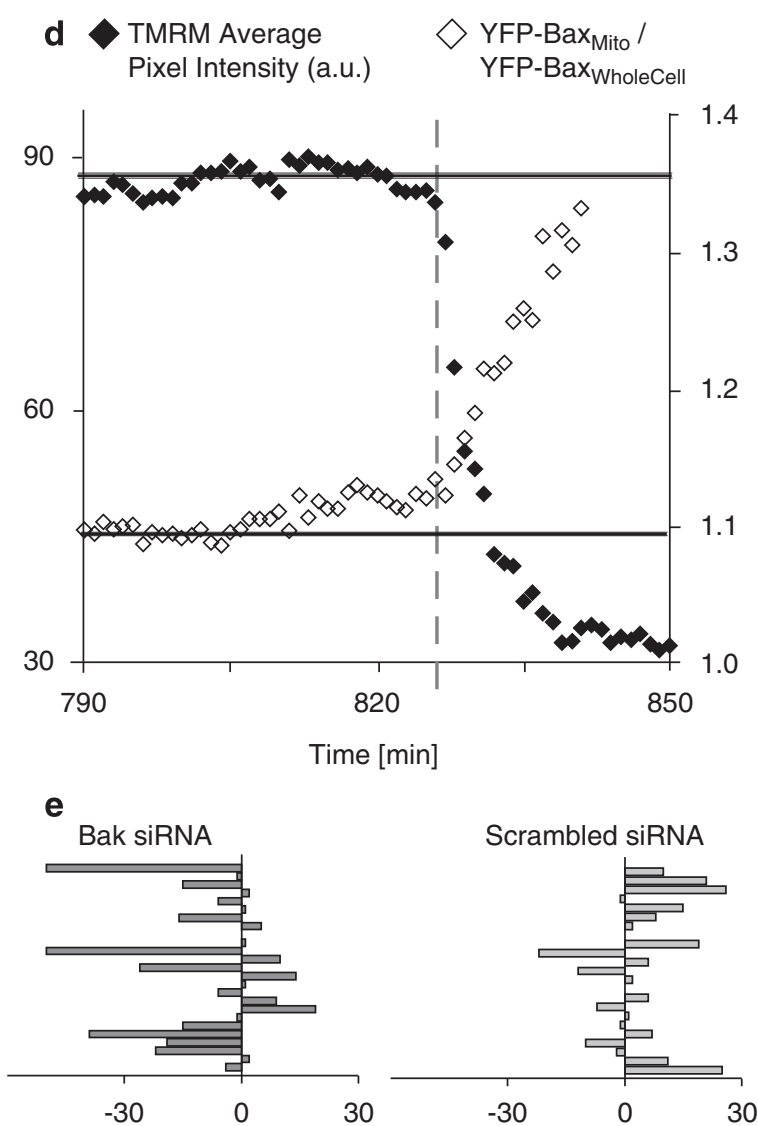

Onset Time of YFP-Bax Translocation [min]

Onset Time of YFP-Bax Translocation [min]

f

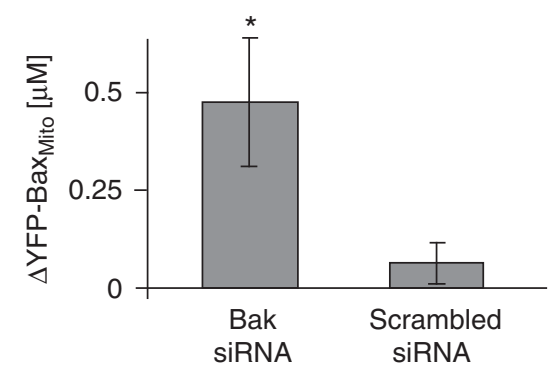


mitochondrial membrane. At the late stages of apoptosis, we detected an increase in Bax-FRET in the cytoplasmic compartment encompassing TMRM-negative mitochondria. This was likely due to Bax-FRET signals originating from fully depolarised mitochondria or from the formation of mitochondria-associated Bax clusters. ${ }^{31}$

MOMP as an ultra-sensitive systems response. Cell death signalling must occur in a strictly controlled manner

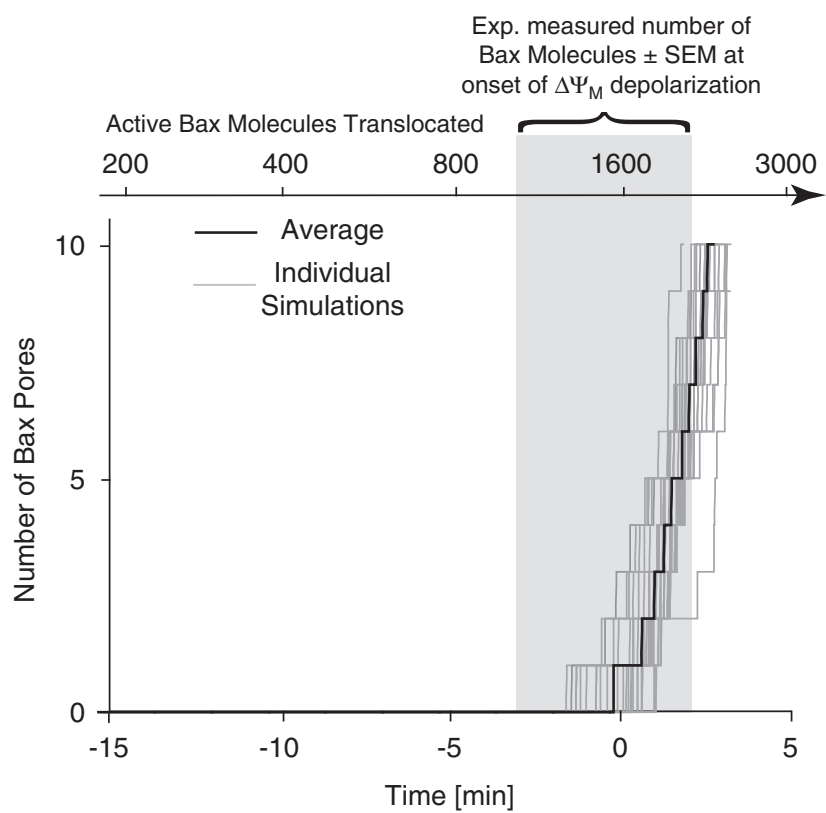

Figure 6 Cellular automaton modelling of mitochondrial Bax pore formation. The cellular automaton model calculated the interplay of Bax/Bak proteins, activator and enabler $\mathrm{BH}-3$-only proteins, and anti-apoptotic $\mathrm{Bcl}-2$ family proteins in the outer mitochondrial membrane using the 'direct activation' model. The mitochondrion was modelled with a surface area of $4 \mu \mathrm{m}^{2}$ and represented by a grid of $20 \mathrm{~nm}$ mesh size. The ordinate indicates the number of Bax pores, the abscissa indicates the simulation time with discrete minimal time intervals set to $0.5 \mathrm{~s}$ to update the simulation stepwise. The formation of pores occurs on formation of Bax tetramers or higher oligomers (see Materials and Methods and Supplementary Figure 3, as well as the animation of the CA as Supplementary Movie). Single simulations and the average pore formation kinetics are represented by the grey traces and the black trace, respectively. The grey shadow underlying the traces outlines the time frame, which corresponds to the experimentally determined concentration change of YFPBax $_{\text {Mito }} \pm$ S.E.M. that was observed at the onset of $\Delta \Psi_{M}$ depolarisation. The corresponding number of translocated active Bax molecules is indicated parallel to the abscissa on top of the graph. The modelling approach successfully calculated rapid pore formation at experimentally determined YFP-Bax concentrations to avoid the accumulation of cells that are damaged but continue to function or rather dysfunction in a cellular network. Strict cell death signalling also avoids cells continuing to proliferate despite having significant damages to their genome. Earlier studies have demonstrated that the key steps during apoptosis, MOMP and effector caspase activation frequently occur as all-or-none, switch-like processes. ${ }^{10,12,32,33}$ However, how the translation of a continuous cellular stress signal into a rapid, switch-like cell death process is being achieved is still a matter of debate. ${ }^{26}$ Our quantitative single-cell imaging of the process of YFPBax translocation and oligomerisation during apoptosis demonstrated that MOMP may proceed when only a small fraction of Bax is activated. The process of Bax oligomers acquiring the capacity to release mitochondrial intermembrane space proteins functionally resembles the characteristics of an ultra-sensitive process: The pore forming ability of individual Bax multimers increases from zero to its maximum as soon as tetramers or higher order Bax oligomers form. Further, the CA model used in this study suggests that following an initial lag time, the formation of the first pore is followed by multiple additional pores in rapid succession. Indeed, in support of this, Bax oligomers activated in synthetic membranes were shown to rapidly form release channels. ${ }^{34}$ It is notable that these characteristics emanated from the model without requiring positive feedback or feed-forward signalling loops, which frequently are pre-requisite for ultra-sensitive systems behaviour. ${ }^{35}$ Self-amplifying cascades of active Bax molecules activating inactive Bax molecules, as suggested earlier, ${ }^{36}$ may therefore not be necessary for efficient MOMP, but could make the Bax pore formation process even more rapid. Finally, spatial factors, in particular the accumulation of Bax in specific mitochondrial compartments such as OM and IM contact points, may further facilitate the release of mitochondrial intermembrane or intracristae proteins.

Robustness of Bax/Bak-dependent MOMP. Earlier studies have demonstrated that the combined knock-out of the bax and bak genes in transgenic mice, or a combined knock-down of both genes in human cancer cells is required to fully inhibit the process of MOMP during most forms of stress-induced apoptosis. ${ }^{2}$ The main activation of Bax appears to involve translocation from the cytoplasm to mitochondria, whereas Bak is in an inactive form already present at mitochondria. Importantly, both signalling systems

Figure 5 Elevated amounts of YFP-Bax are required to induce MOMP in Bak-depleted cells. (a) Efficient siRNA-mediated Bak depletion in DU-145 cells. Bak expression was probed by immunoblotting $24 \mathrm{~h}$ after transient transfection with either Bak specific siRNA or scrambled control siRNA. $\alpha$-Tubulin served as loading control. (b) Quantification of apoptosis in Bak-silenced DU-145 cells. Cells were exposed to $1 \mu \mathrm{M} \mathrm{STS}, 100 \mathrm{ng} / \mathrm{ml}$ TRAlL (plus $1 \mu \mathrm{g} / \mathrm{ml} \mathrm{CHX)} \mathrm{or} \mathrm{vehicle} \mathrm{for} 6 \mathrm{~h}$ and subsequently stained. Apoptosis was quantified from fragmented nuclear morphology (Hoechst stain) and low mitochondrial membrane potential (Mito Tracker red). Data are means \pm S.E.M. from $n=6$ independent treatments. (c) A representative Bak-depleted DU-145 cell expressing YFP-Bax. The cell was treated with $3 \mu \mathrm{M}$ STS and imaged at 1 frame per minute. The TMRM channel was used to segment polarised mitochondrial regions. The pseudo-colour scale indicates the mitochondrial YFP-Bax concentrations corresponding to the measured fluorescence intensities. Time stamps indicate time after stimulus addition. (d) YFP-Bax translocation kinetic plotted for the cell shown in (c). The dashed vertical line indicates the onset of $\Delta \Psi_{\mathrm{M}}$ depolarisation. Onset of YFP-Bax translocation pronouncedly preceded the onset of mitochondrial depolarisation. (e) The onset time of YFP-Bax translocation in individual cells was plotted relative to the onset time of $\Delta \Psi_{\mathrm{M}}$ depolarisation (normalised to time zero) after treatment with $3 \mu \mathrm{M} \mathrm{STS}$. (f) The concentration change of mitochondrial YFP-Bax measured at the onset of $\Delta \Psi_{M}$ depolarisation was quantified from bak-silenced and control cells. Significantly higher amounts of YFP-Bax have translocated at the onset of $\Delta \Psi_{\mathrm{M}}$ depolarisation in bak-silenced cells when compared with cells transfected with control siRNA. Data are shown as mean \pm S.E.M. ( ${ }^{*}$ Significant, $P=0.006$, Student's $t$-test, $n=23$ cells from 10 experiments in bak-silenced and $n=25$ cells from four control experiments) 
are believed to show significant redundancy, with active $\mathrm{BH}$-only proteins potentially able to activate both Bax and Bak when in biological membranes. ${ }^{37}$ Furthermore, there is a significant overlap in the ability of anti-apoptotic Bcl-2 family proteins to inhibit Bax and Bak, and most BH3-only proteins are able to relieve this inhibition. ${ }^{38}$ Our imaging studies and mathematical modelling approach indirectly support these observations. Significantly higher amounts of activated YFP-Bax molecules were detected at mitochondria of cells silenced for bak expression compared with control DU-145 cells at the time point of mitochondrial depolarisation. However, both our experimental and mathematical modelling results suggest that cells can still undergo a rapid and efficient pore formation and mitochondrial depolarisation in the absence of Bak. Both the functional redundancy of Bax and Bak as well as the excess of Bax (and potentially Bak) activation may provide a high degree of robustness for the MOMP process towards a perturbation of this signalling system. ${ }^{39}$ Such perturbations can rise from cell-cycle-dependent variations of gene and protein expression, from cell-to-cell differences in gene or protein expression, or during the process of transformation.

Preventing unwanted apoptosis. Perhaps one of the most challenging questions is how, if apoptosis is such a terminal process for the cell and MOMP is triggered already at a low thresholds of activated Bax, unwanted apoptosis can be avoided under physiological, mild or transient stress conditions. Clearly, minimal activation of active Bax will be absorbed by anti-apoptotic Bcl-2 family proteins. However, a key determinant of the cell survival/cell death switch might also be the kinetics of the generation of Bax or Bak activators or enablers, in particular the generation of $\mathrm{BH} 3$-only proteins. A biological system thus would require a strict control of the activation of these proteins or genes. In a recent study using a YFP-Bid-CFP FRET probe in caspase-3-deficient MCF-7 cells, we could already demonstrate that the activation of the $\mathrm{BH} 3-$ only protein Bid may be under such a strict control. ${ }^{29}$ The kinetics of the generation of other $\mathrm{BH} 3-$ only proteins or Bax/Bak activators and enablers, in particular their transcriptional activation, clearly warrants further investigation.

\section{Conclusion}

Our study provides quantitative data on the process of Bax activation in intact cells and suggests that the process of Bax pore formation and MOMP may be an ultra-sensitive and robust process. Similar to Cyt-C-induced apoptosome formation, there appears to exist an excess availability of key apoptosis-inducing factors, potentially to overcome any block in the cell death execution system, such as variations in the level of Bcl-2 subfamily member expression.

\footnotetext{
Materials and Methods

Cell culture and transfection. Human prostate cancer DU-145 cells that do not express endogenous $\mathrm{Bax}^{40}$ were cultured in DMEM with glucose $(4.5 \mathrm{~g} / \mathrm{l})$, penicillin $(100 \mathrm{U} / \mathrm{ml})$, streptomycin $(100 \mu \mathrm{g} / \mathrm{ml})$ and $10 \%$ fetal calf serum (Sigma, Dublin, Ireland).
}

The CFP and YFP plasmids (pCFP-N1; pYFP-N1) were received from (Clontech, Palo Alto, CA, USA). bax cDNA was kindly provided by the late Dr. Stanley Korsmeyer. Cloning of bax into the plasmids was performed as described earlier. ${ }^{24}$ DU-145 cells were transfected with $0.6 \mu \mathrm{g}$ of plasmid DNA (CFP-Bax or YFP-Bax) and $6 \mu \mathrm{l} \mathrm{Lipofectamin} 2000$ per $\mathrm{ml}$ serum-free culture medium at $37^{\circ} \mathrm{C}$ for $4 \mathrm{~h}$. For the generation of stable cell lines, transfected cells were selected in the presence of $1 \mathrm{mg} / \mathrm{ml} \mathrm{G} 418$ for 2 weeks and fluorescent clones were enriched. Transient transfections in DU-145 cells were performed on glass-bottomed dishes (Willco BV, Amsterdam, The Netherlands) using $150 \mu \mathrm{l}$ serum-free culture medium, $70 \mathrm{ng}$ plasmid DNA encoding for YFP-Bax, $200 \mathrm{ng}$ siRNA against Bak (see below) or $200 \mathrm{ng}$ scrambled RNA, and $0.5 \mu \mathrm{l}$ Metafectene. Cells were used 24 to $60 \mathrm{~h}$ after transfection. The HeLa clone stably expressing CFP-DEVD-YFP used as a positive control for FRET has been described earlier. ${ }^{32}$

Immunoblotting. Immunoblotting was performed as described earlier, ${ }^{9}$ for details of extract preparation and antibodies used see online Supplementary material.

Immunohistochemistry. DU-145 cells and DU-145 cells stably expressing YFP-Bax were grown onto chambered cover glass slides (Labtek) for 2 days and then treated with dimethylsulfoxide (DMSO; $0.1 \% \mathrm{v} / \mathrm{v}$ ), TNF-related apoptosis inducing ligand (TRAIL; $100 \mathrm{ng} / \mathrm{ml}$; Leinco Technologies, Universal Biologicals, Ltd., Cambridge, UK) plus $1 \mu \mathrm{g} / \mathrm{ml}$ cycloheximide (TRAIL/CHX), or STS $(1 \mu \mathrm{M}$; both from Alexis Corporation, Nottingham, UK). After $6 \mathrm{~h}$ of treatment, cells were washed with phosphate-buffered saline (PBS), and then fixed using $4 \%$ paraformaldehyde in PBS for $20 \mathrm{~min}$. Cells were permeabilised with $0.1 \%$ Tween- 20 and blocked with $5 \%$ horse serum before incubation with Bax 6A7 antibody (Becton Dickinson, Heidelberg, Germany) 1:50 in $75 \mu \mathrm{l} \mathrm{PBS} / 3 \%$ horse serum). The antibody was then labelled with rabbit biotin (Jackson Immuno Research Europe, Suffolk, UK, 1:500), and with Alexa 594 Streptavidin (Molecular Probes, Leiden, Netherlands, 1:1000). The $6 A 7$ antibody recognises the amino acids $12-24,{ }^{17}$ which are exposed on activation of the Bax molecule. Alternatively, cells were incubated with monoclonal Cyt-C antibody (clone 6H2.B4; PharMingen, Becton Dickinson), which recognises the native form of $\mathrm{Cyt}-\mathrm{C}$. The antibody was used at a concentration of 1:500 in PBS containing 1\% horse serum and 0.3\% Tween-20. After incubation at room temperature for $4 \mathrm{~h}$, cells were washed twice with PBS and incubated with biotin-conjugated mouse IgG antibody (Vector Laboratories, Burlingame, CA, USA) diluted 1:500 for $60 \mathrm{~min}$. The fluorescence label was Alexa 594-conjugated streptavidin diluted 1:1000 in PBS and incubated for $60 \mathrm{~min}$ at room temperature.

Confocal images were scanned on a LSM 510 Meta (Carl Zeiss, Oberkochen, Germany) using a $63 \times 1.4$ NA oil immersion DIC objective and the $488 \mathrm{~nm}$ laser line of an Argon laser to excite YFP, a $488 \mathrm{~nm}$ dichroic and $505-550 \mathrm{~nm}$ band pass emission filter. Alexa 594 was excited with a $543 \mathrm{~nm}$ HeNe-Laser and detected with a $488 / 543 \mathrm{~nm}$ multichroic and $575 \mathrm{LP}$ filter. The optical slice was set to $0.8 \mu \mathrm{m}$ (FWHM) for both channels. Control incubation with secondary antibodies only did not show a signal above noise with the same settings.

Quantification of apoptosis. DU-145 cells have been shown earlier to be re-sensitised by the ectopic expression of Bax to stimuli such as over expression or photodynamic therapy. ${ }^{41,42}$ Likewise, GFP-Bax has been shown earlier to promote apoptosis similar to endogenous Bax. ${ }^{3}$ To evaluate the levels of apoptosis in DU145 cells and DU-145 cells expressing YFP-Bax, cells were seeded into 24-well plates, treated with $1 \mu \mathrm{M}$ STS $(6 \mathrm{~h}), 50 \mathrm{ng} / \mathrm{ml}$ TRAIL and $1 \mu \mathrm{g} / \mathrm{ml} \mathrm{CHX}(6 \mathrm{~h})$, or vehicle (DMSO, $6 \mathrm{~h}$ ). Subsequently, cells were stained with $100 \mathrm{ng} / \mathrm{ml}$ Hoechst 33258, and $50 \mathrm{nM}$ Mitotracker Red or (Molecular Probes, Leiden, The Netherlands) $30 \mathrm{~min}$ before fixation. Images were taken using a Nikon TE 300 equipped with a $20 \times$, NA 0.45 phase contrast objective and a CCD camera (SPOT RT SE 6 , Diagnostic Instruments, Sterling Heights, MI, USA) using the appropriate filter sets for Hoechst, YFP (where applicable), Mitotracker Red, and the phase contrast image. The percentage of apoptotic cells was determined by counting fragmented and condensed nuclei and verified by intracellular distribution of Mitotracker Red and cellular morphology with overlay images and the cell counter plug-in for ImageJ (http://rsb.info.nih.gov/ij).

Confocal live cell imaging. DU-145 cells stably transfected with the plasmids encoding for CFP-Bax, YFP-Bax, YFP, CFP or transiently transfected with plasmids encoding for YFP-Bax plus siRNA for Bak (siBak) or control siRNA (scrambled, siSCR) were loaded with TMRM $(30 \mathrm{nM})$ for $30 \mathrm{~min}$ at $37^{\circ} \mathrm{C}$ in the dark. The glass-bottom dishes were placed on the heated $\left(37^{\circ} \mathrm{C}\right)$ stage of a confocal 
microscope with a $63 \times, 1.4$ NA DIC objective with heater (LSM 510 Meta, Carl Zeiss). Apoptosis was induced with $100 \mathrm{ng} / \mathrm{ml}$ TRAIL plus $1 \mu \mathrm{g} / \mathrm{ml} \mathrm{CHX} \mathrm{or} 3 \mu \mathrm{M}$ STS $30 \mathrm{~min}$ after the start of live-cell imaging. To observe an increase in the FRET efficiency between CFP-Bax and YFP-Bax, the CFP (FRET-donor) was excited at $405 \mathrm{~nm}$ with a $30 \mathrm{~mW}$ laser diode adjusted to $2 \%$ of total intensity reflected by a $405 / 514 \mathrm{~nm}$ beam splitter. CFP and YFP (FRET-acceptor) emission were collected through $470-500 \mathrm{~nm}$ and $505-550 \mathrm{~nm}$ band pass filters, respectively. For direct excitation of YFP, the $488 \mathrm{~nm}$ laser line of the Argon laser ( $50 \%$ of maximal power AOTF attenuated to $0.5 \%$ transmission) was used, and the emission was collected through a $505-550 \mathrm{~nm}$ band pass filter. The resolution along the optical axis was set to the same value for all channels in each experiment (2-2.5 $\mu \mathrm{m}$ FWHM). For YFP. Bax translocation measurements, YFP settings were similar as above except for the AOTF attenuated to $2-5 \%$ transmission at $488 \mathrm{~nm}$ and a resolution along the optical axis of $1.5 \mu \mathrm{m}$ (FWHM). These adjustments allowed live cell imaging without any detectable phototoxicity after $24 \mathrm{~h}$ control time-lapse measurements with a minimised trade off on resolution and contrast.

Analysis of mitochondrial membrane potential kinetics. MOMP induces a rapid, initially caspase-independent $\Delta \Psi_{\mathrm{M}}$ depolarisation that can be detected with TMRM. ${ }^{9}$ TMRM was excited with a Helium Neon laser (4-5\%) at $543 \mathrm{~nm}$ and a $560 \mathrm{~nm}$ long pass emission filter. Images were taken at the same frequency as for the Bax signalling detection. Control experiments revealed that TMRM was retained in mitochondria during the time span of these experiments, and that control cells remained viable and underwent mitosis (Supplementary Figure 5). Image processing and analysis was performed using MetaMorph software. All $\Delta \Psi_{\mathrm{M}}$ kinetics were fitted with the sigmoid Boltzmann equation

$$
F(t)=\left(F_{1}-F_{0}\right) /\left(1+\mathrm{e}^{\left\{\left[t-t_{0}\right] / \Delta t\right\}}\right)+F_{0}
$$

with $\Delta t$ determining the width of the turnover, $F_{1}$ the minimum, $F_{0}$ the maximum, and $t_{0}$ the time point when $\left(F_{0}-F_{1}\right) / 2$ is reached, using OriginPro 7.5 (OriginLab Corporation, Northampton, MA, USA). A difference of more than the S.D. below the initial baseline $\left(F_{0}-\Delta F_{0}\right)$, which did not recover to baseline values, was defined as onset time of mitochondrial membrane potential depolarisation.

Time-lapse FRET analysis of CFP-Bax/YFP-Bax protein interaction. HeLa cells stably expressing equal amounts of donor and acceptor molecules in a highly efficient FRET probe (CFP-DEVD-YFP) ${ }^{32}$ were used to determine the apparent FRET efficiency (E-FRET) between CFP and YFP when measuring at the settings described above. ${ }^{43}$ Acceptor photobleaching was performed with $100 \%$ of the $514 \mathrm{~nm}$ argon laser line. Crosstalk from CFP and YFP into the FRET channel was determined to be $38 \%$ of the CFP and $8 \%$ of the YFP fluorescence. Other crosstalks were negligible. All crosstalk values were determined with DU-145 cells transiently transfected with YFP or CFP alone. After crosstalk correction of the FRET channel, E-FRET was calculated by $R /(R+G)$, where $R$ equals the ratio of FRET intensity divided by CFP intensity and $G$ the instrument factor of the Zeiss LSM 510 Meta confocal microscope $(G=3.5)$. Acceptor photobleaching was done as described above to prove intermolecular FRET in oligomers of CFP- and YFP-Bax fusion proteins.

In the following we will refer to the apparent FRET efficiency as FRET. All FRET kinetics were fitted using the sigmoid Boltzmann equation as stated above. A difference of more than the S.D. off the initial baseline, which did not recover to baseline values, was chosen to be the onset time of the signalling $\left(F_{0}+\Delta F_{0}\right)$. The S.D. of the baseline is allowed to detect an increase of $\mathrm{FRET}_{\text {Mito }}$ at $10 \%$ and of FRET $_{\text {Cyto }}$ as low as $0.8 \%$ of the baseline. The first S.D. is higher because of the lower number of pixels the average intensity was calculated from.

Spatial discrimination of intact mitochondria in time-lapse oligomerisation and translocation measurements. MOMP is paralleled by a sharp decrease in mitochondrial membrane potential. ${ }^{9}$ Subcellular segmentation was performed using the TMRM signal and enabled us to separate early Bax translocation to, and interaction at, polarised mitochondria (index: 'Mito') from translocation to/interaction at depolarised, 'apoptotic' mitochondria or any other compartment of the cell (index: 'Cyto'). The 'Mito' compartment was segmented with an intensity threshold above the cellular background. This was determined to be above an intensity of 25 grey levels in the 8-bit images. The onset of the accumulation of YFP-Bax at polarised mitochondria was determined in relation to the ratio $R=\mathrm{F}\left(\left[\mathrm{YFP}_{\text {Mito }}\right]\right) / \mathrm{F}\left(\left[\mathrm{YFP}_{\text {Whole }}\right.\right.$ Cell $\left.]\right)$, indicating the relative increase of YFP-Bax in polarised mitochondria. The baseline S.D. of this ratio determined the sensitivity of this readout (Figures $4 b$ and $5 b$ ). Image processing and analysis was performed using MetaMorph software (7.0r1-4, Molecular Devices, Berkshire, UK).

YFP fluorescence calibration. YFP was diluted to $0.1,0.5,1,5,10,20$ and $100 \mu \mathrm{M}$ aqueous solutions containing $10 \mathrm{mM}$ bovine serum albumin (Sigma, Dublin, Ireland). Droplets were added onto glass bottom petri dishes (Willco Wells, Amsterdam, The Netherlands), which were pre-incubated with a $10 \mathrm{mM}$ BSA solution for $30 \mathrm{~min}$ in humidified atmosphere. Droplets were covered with embryotested mineral oil (Sigma) and fluorescence intensity was measured on the LSM 510 Meta as described above. The excitation intensity was reduced for high concentrations and the intensity measurements for the calibration curve corrected accordingly (see Figure 4a). BSA autofluorescence was subtracted from all measurements and a calibration curve was fitted (Microcal, Origin 7.5). For each calibration experiment as well as for each quantitative YFP-Bax translocation experiment, the excitation intensities were corrected for long-term instabilities of the light source. To this end, the intensity of the $488 \mathrm{~nm}$ Argon laser line reflected off a glass slide was measured at a tube current of $6 \mathrm{~A}$ ( $50 \%$ laser power)

CA model of MOMP. To understand the kinetics of processes leading to MOMP and to study timing of pore formation with regard to Bax activation we used a CA model. ${ }^{23}$ To this end, the protein interactions on the outer membrane of a single mitochondrion $\left(\sim 4 \mu \mathrm{m}^{2}\right)$ were modelled by a discrete mesh of $100 \times 100$ squares with periodic boundaries and zero to seven proteins being located at each grid point. Each grid space thus represents an area of $20 \times 20 \mathrm{~nm}$. In each discrete time step, proteins move between neighbouring grid spaces by random walk with a mobility calculated from the protein mass. Biochemical interactions occur for proteins co-located in the same grid spaces with a reaction partner-specific probability. 22 Biochemical reactions were modelled to include a two-step activation of inactive Bax to fully active $B a x\left(A c B a x^{*}\right)$ in two different scenarios:

'Direct activation' model: AcBax , defined as fully activated Bax enabling pore formation, is generated through (1) a translocation step of a partially activated Bax protein (AcBax; e.g. with an externalised alpha 9 helix) that is not sensitive to Bcl-2 inhibition, followed by (2) a full activation step generating $\mathrm{AcBax}^{*}$ (e.g. with an additional externalisation of alpha helices 5 and 6 ) by an activator (e.g. tBid):

$$
\text { AcBax }+ \text { Activator } \rightarrow \text { AcBax } *+\text { Activator }
$$

The probability that the reaction takes place when both molecules occupy the same mitochondrial outer membrane surface element is 0.5 within $0.5 \mathrm{~s}$ (Figure 6).

'Indirect activation' model: Here, AcBax is also formed in a two-step reaction; however, the second activation step was modelled to occur 'spontaneously' (or in a not further specified manner in the absence of direct activators) at different probability rates:

$$
\mathrm{AcBax} \rightarrow \mathrm{AcBax} * \text {. }
$$

This 'spontaneous' reaction was associated with rate constants $k$ varying from 1 in 1000 to 10 in 1000 activation events per modelled time interval $(0.5 \mathrm{~s})$.

$\mathrm{AcBax}^{*}$ and Activator (in the case of the 'direct activation' model) were modelled to be inhibited by anti-apoptotic proteins of the Bcl-2 family (such as Bcl-2, Bcl-xl or Mcl-1). Enabler proteins were modelled to bind anti-apoptotic Bcl-2 proteins competitively, thus liberating $\mathrm{AcBax}{ }^{*}$ or the activator (in the case of the 'direct activation' model) from the heteromeric complexes. Oligomerisation of AcBax* into a tetramer or a higher oligomer was considered to constitute a pore. ${ }^{34}$ The experimentally determined Bax concentration and translocation kinetics shown in this study were included into the model. The model was implemented in MATLAB (The Mathworks, UK). Codes are available on request. Further information on this modelling approach is included in the Supplementary Materials and Methods description.

Statistical analysis. Statistical tests were performed as outlined in the respective figure legends and results using SPSS 15 (LEAD Technologies, Chicago, IL, USA).

Acknowledgements. We thank Hannes Herzel for technical support and Dr. Peter Daniel (Charité, Humboldt University, Berlin) for DU-145 and DU-145-Bax cells. This research was supported by grants from Science Foundation Ireland (03/RP1/B344; 08/IN1/1949), the Irish Health Research Board (RP/2006/258), the National Biophotonics and Imaging Platform Ireland (Higher Education Authority PRTLI Cycle 4), the European Union (FP 7 Health-APO-SYS), and by Siemens Ireland. 
1. Green DR, Kroemer G. The pathophysiology of mitochondrial cell death. Science 2004; 305: 626-629.

2. Wei MC, Zong W-X, Cheng EHY, Lindsten T, Panoutsakopoulou V, Ross AJ et al. Proapoptotic BAX and BAK: a requisite gateway to mitochondrial dysfunction and death. Science 2001; 292: 727-730.

3. Wolter KG, Hsu Y-T, Smith CL, Nechushtan A, Xi X-G, Youle RJ. Movement of Bax from the Cytosol to mitochondria during apoptosis. J Cell Biol 1997; 139: 1281-1292.

4. Desagher S, Osen-Sand A, Nichols A, Eskes R, Montessuit S, Lauper S et al. Bid-induced conformational change of $\mathrm{Bax}$ is responsible for mitochondrial cytochrome $\mathrm{c}$ release during apoptosis. J Cell Biol 1999; 144: 891-901.

5. Kuwana T, Mackey MR, Perkins G, Ellisman MH, Latterich M, Schneiter R et al. Bid, Bax, and lipids cooperate to form supramolecular openings in the outer mitochondrial membrane. Cell 2002; 111: 331.

6. Nechushtan A, Smith CL, Lamensdorf I, Yoon SH, Youle RJ. Bax and Bak coalesce into novel mitochondria-associated clusters during apoptosis. J Cell Biol 2001; 153: 1265-1276.

7. Lovell JF, Billen LP, Bindner S, Shamas-Din A, Fradin C, Leber B et al. Membrane binding by tBid initiates an ordered series of events culminating in membrane permeabilization by Bax. Cell 2008; 135: 1074-1084.

8. Annis MG, Soucie EL, Dlugosz PJ, Cruz-Aguado JA, Penn LZ, Leber B et al. Bax forms multispanning monomers that oligomerize to permeabilize membranes during apoptosis. EMBO J 2005; 24: 2096-2103

9. Dussmann H, Rehm M, Kogel D, Prehn JHM. Outer mitochondrial membrane permeabilization during apoptosis triggers caspase-independent mitochondrial and caspase-dependent plasma membrane potential depolarization: a single-cell analysis. J Cell Sci 2003; 116: 525-536.

10. Goldstein JC, Waterhouse NJ, Juin P, Evan GI, Green DR. The coordinate release of cytochrome $\mathrm{c}$ during apoptosis is rapid, complete and kinetically invariant. Nat Cell Biol 2000; 2: 156-162.

11. Munoz-Pinedo C, Guio-Carrion A, Goldstein JC, Fitzgerald P, Newmeyer DD, Green DR Different mitochondrial intermembrane space proteins are released during apoptosis in a manner that is coordinately initiated but can vary in duration. PNAS 2006; 103: 11573-11578.

12. Rehm M, Dussmann H, Prehn JHM. Real-time single cell analysis of Smac/DIABLO release during apoptosis. J Cell Biol 2003; 162: 1031-1043.

13. Li H, Zhu H, Xu CJ, Yuan J. Cleavage of BID by caspase 8 mediates the mitochondria damage in the Fas pathway of apoptosis. Cell 1998; 94: 491-501.

14. Kroemer G, Martin SJ. Caspase-independent cell death. Nat Med 2005; 11: 725-730.

15. Rehm M, Huber HJ, Hellwig CT, Anguissola S, Dussmann H, Prehn JH. Dynamics of outer mitochondrial membrane permeabilization during apoptosis. Cell Death Differ 2009; 16 613-623.

16. von Haefen C, Wieder T, Gillissen B, Starck L, Graupner V, Dorken B et al. Ceramide induces mitochondrial activation and apoptosis via a Bax-dependent pathway in human carcinoma cells. Oncogene 2002; 21: 4009-4019.

17. Hsu YT, Youle RJ. Nonionic detergents induce dimerization among members of the Bcl-2 family. J Biol Chem 1997; 272: 13829-13834.

18. Peyerl FW, Dai S, Murphy GA, Crawford F, White J, Marrack $P$ et al. Elucidation of some Bax conformational changes through crystallization of an antibody-peptide complex. Cell Death Differ 2006; 14: 447.

19. Heiskanen KM, Bhat MB, Wang HW, Ma J, Nieminen AL. Mitochondrial depolarization accompanies cytochrome c release during apoptosis in PC6 cells. J Biol Chem 1999; 274: $5654-5658$

20. Mootha VK, Wei MC, Buttle KF, Scorrano L, Panoutsakopoulou V, Mannella CA et al. A reversible component of mitochondrial respiratory dysfunction in apoptosis can be rescued by exogenous cytochrome c. EMBO J 2001; 20: 661-671.

21. Waterhouse NJ, Goldstein JC, von Ahsen O, Schuler M, Newmeyer DD, Green DR. Cytochrome $\mathrm{c}$ maintains mitochondrial transmembrane potential and ATP generation after outer mitochondrial membrane permeabilization during the apoptotic process. $J$ Cell Biol 2001; 153: 319-328.
22. Chen C, Cui J, Lu H, Wang R, Zhang S, Shen P. Modeling of the role of a Bax-activation switch in the mitochondrial apoptosis decision. Biophys J 2007; 92: 4304-4315.

23. Siehs C, Oberbauer R, Mayer G, Lukas A, Mayer B. Discrete simulation of regulatory homo- and heterodimerization in the apoptosis effector phase. Bioinformatics 2002; 18: $67-76$.

24. Luetjens CM, Kogel D, Reimertz C, Dussmann H, Renz A, Schulze-Osthoff K et al. Multiple kinetics of mitochondrial cytochrome $\mathrm{c}$ release in drug-induced apoptosis. Mol Pharmacol 2001; 60: 1008-1019.

25. Smaili SS, Hsu YT, Sanders KM, Russell JT, Youle RJ. Bax translocation to mitochondria subsequent to a rapid loss of mitochondrial membrane potential. Cell Death Differ 2001; 8 909-920.

26. Albeck JG, Burke JM, Spencer SL, Lauffenburger DA, Sorger PK. Modeling a snap-action, variable-delay switch controlling extrinsic cell death. PLOS Biol 2008; 6: 2831-2852.

27. Lartigue L, Medina C, Schembri L, Chabert P, Zanese M, Tomasello F et al. An intracellular wave of cytochrome $\mathrm{C}$ propagates and precedes Bax redistribution during apoptosis. J Cell Sci 2008; 121 (Pt 21): 3515-3523.

28. Zhou L, Chang DC. Dynamics and structure of the Bax-Bak complex responsible for releasing mitochondrial proteins during apoptosis. J Cell Sci 2008; 121 (Pt 13): 2186-2196.

29. Ward MW, Rehm M, Duessmann H, Kacmar S, Concannon CG, Prehn JHM. Real time single cell analysis of BID cleavage and BID translocation during caspase-dependent and neuronal caspase-independent apoptosis. J Biol Chem 2005; 281: 5837-5844.

30. Gross A, Jockel J, Wei MC, Korsmeyer SJ. Enforced dimerization of BAX results in its translocation, mitochondrial dysfunction and apoptosis. EMBO J 1998; 17: 3878-3885.

31. Nechushtan A, Smith CL, Hsu YT, Youle RJ. Conformation of the Bax C-terminus regulates subcellular location and cell death. EMBO J 1999; 18: 2330-2341.

32. Rehm M, Dussmann H, Janicke RU, Tavare JM, Kogel D, Prehn JHM. Single-cell fluorescence resonance energy transfer analysis demonstrates that caspase activation during apoptosis is a rapid process. ROLE OF CASPASE-3. J Biol Chem 2002; 277 24506-24514.

33. Rehm M, Huber HJ, Dussmann H, Prehn JHM. Systems analysis of effector caspase activation and its control by $\mathrm{X}$-linked inhibitor of apoptosis protein. EMBO J 2006; 25: 4338-4349.

34. Saito $\mathrm{M}$, Korsmeyer SJ, Schlesinger $\mathrm{PH}$. BAX-dependent transport of cytochrome $\mathrm{C}$ reconstituted in pure liposomes. Nat Cell Biol 2000; 2: 553

35. Pomerening JR. Uncovering mechanisms of bistability in biological systems. Curr Opin Biotechnol 2008; 19: 381-388.

36. Tan C, Dlugosz PJ, Peng J, Zhang Z, Lapolla SM, Plafker SM et al. Auto-activation of the apoptosis protein $\mathrm{BAX}$ increases mitochondrial membrane permeability and is inhibited by BCL-2. J Biol Chem 2006; 281: 14764-14775.

37. Korsmeyer SJ, Wei MC, Saito M, Weiler S, Oh KJ, Schlesinger PH. Pro-apoptotic cascade activates BID, which oligomerizes BAK or BAX into pores that result in the release of cytochrome c. Cell Death Differ 2000; 7: 1166-1173.

38. Letai AG. Diagnosing and exploiting cancer's addiction to blocks in apoptosis. Nat Rev Cancer 2008; 8: 121-132.

39. Kitano H. Biological robustness. Nat Rev Genet 2004; 5: 826-837.

40. Marcelli M, Marani M, Li X, Sturgis L, Haidacher SJ, Trial JA et al. Heterogeneous apoptotic responses of prostate cancer cell lines identify an association between sensitivity to staurosporine-induced apoptosis, expression of $\mathrm{Bcl}-2$ family members, and caspase activation. Prostate 2000; 42: 260-273.

41. Chiu SM, Xue LY, Usuda J, Azizuddin K, Oleinick NL. Bax is essential for mitochondrion-mediated apoptosis but not for cell death caused by photodynamic therapy. Br J Cancer 89: 1590.

42. Li X, Marani M, Yu J, Nan B, Roth JA, Kagawa S et al. Adenovirus-mediated Bax overexpression for the induction of therapeutic apoptosis in prostate cancer. Cancer Res 2001; 61: 186-191.

43. Zal T, Gascoigne NRJ. Photobleaching-corrected FRET efficiency imaging of live cells Biophys J 2004; 86: 3923-3939.

Supplementary Information accompanies the paper on Cell Death and Differentiation website (http://www.nature.com/cdd) 